Research Journal of Biological Sciences 5 (1): 61-63, 2010

ISSN: $1815-8846$

(C) Medwell Journals, 2010

\title{
Mycoplasma Sp. Detected in the Airways of Normal Healthy Subjects
}

\author{
${ }^{1}$ A. Rivera, ${ }^{2}$ E. Rivera, ${ }^{1} \mathrm{C}$. Gil, ${ }^{2}$ R. Perez-y-Terron, ${ }^{3} \mathrm{~S}$. Giono and ${ }^{1} \mathrm{~L}$. Cedillo \\ ${ }^{1}$ Centro de Investigaciones Microbiológicas del, Instituto de Ciencias de la Benemérita, \\ Universidad Autónoma De Puebla, Puebla, México \\ ${ }^{2}$ Escuela de Biología de la Benemérita, Universidad Autónoma de Puebla, Puebla, México \\ ${ }^{3}$ Laboratorio de Bacteriología Médica del, Departamento de Microbiología, \\ Escuela Nacional de Ciencias Biológicas del, Instituto Politécnico Nacional, D.F. México
}

\begin{abstract}
The lack a rigid cell wall allows direct and intimate contact of the mycoplasma membrane with the cytoplasmic membrane of the host cell. During the fusion process, mycoplasma components are delivered into the host cell and affect the normal functions of the cell. The objective of this study was to determine the frequency of recovery of Mycoplasma sp. in throat swabs from healthy subjects. A microbiological cultures and PCR assay was used to detected mycoplasmas in throat swabs. Two hundred ten subjects provided throats swabs, of which $142(68 \%)$ and $68(32 \%)$ were females and males, respectively. Seventy five swabs cultured in broth and fifty one swabs cultured in agar plates were Mycoplasma sp. positive. PCR detected Mycoplasma sp. far more frequently than culture and these results indicate that mycoplasmas can grow in close interaction with epithelial cells with occurred frequently at mucosal sites in a healthy population.
\end{abstract}

Key words: Mycoplasma, throat swabs, culture and PCR essay, healthy subjects, domestic animals, Mexico

\section{INTRODUCTION}

Mollicutes are prokaryotes that are widely distributed as pathogens and commensals of plants and animals. They include eight recognized genera: Acholeplasma, Anaeroplasma, Entomoplasma, Mesoplasma, Spiroplasma, Asteroplasma, Ureaplasma and Mycoplasma. In humans and domestic animals the majority of Mollicutes isolated belong to the genus Mycoplasma, although, Ureaplasma and certain Acholeplasma sp. may also be present in clinical specimens (Keceli and Miles, 2002). Mycoplasmas represent the smallest self-replicating organisms in both cellular dimensions and genome size that are capable of cell-free existence. The small size and volume of mycoplasma cells allow them to pass through $0.45 \mu \mathrm{M}$ porosize filters that cellular mass also means that mycoplasmas cannot be detected by light microscopy and they do not produce visible turbidity in liquid growth media. Typical colonies rarely exceed $100 \mu \mathrm{M}$ in diameter when cultivated on enriched medium such as SP4 agar and require examination under a stereomicroscope to visualize their morphological features (Waites and Talkington, 2004).

A genomic price had been paid to maintain parasitism, so that a significant number of mycoplasmal genes is devoted to adhesins, attachment organelles and variable membrane surface antigens directed towards evasion of the host immune system (Razin, 1997). The lack a rigid cell wall allows direct and intimate contact of the mycoplasma membrane with the cytoplasmic membrane of the host cell. Under appropriate conditions, such contact may lead to cell fusion. During the fusion process, mycoplasma components (potent hydrolytic enzymes, hydrogen peroxide and superoxide radicals) are delivered into the host cell and affect the normal functions of the cell (Rottem, 2003).

Most Mollicutes lives as commensals and many arthropods they may even be considered symbionts. Infections with pathogenic mycoplasmas are rarely of the fulminant type but rather are close to the concept of ideal parasites, usually living in harmony with their host (Razin et al., 1998). A recent, some what inciting review discusses the role of mycoplasmas in disease pathogenesis, referring also to the variety of diseases of unknown etiology that have been linked to mycoplasmas (Baseman and Tully, 1997).

Recently, Mycoplasma sp. were detected in the airways of humans in absence of symptoms of acute infection and the incidence was greater in asthmatics. Using sensitive PCR-based detection methods, high incidences of Mycoplasma fermentans positively have

Corresponding Author: A. Rivera, Centro de Investigaciones Microbiológicas del, Instituto de Ciencias de la Benemérita, Universidad Autónoma de Puebla, Puebla, México 
been noted in saliva, blood and urine from apparently normal healthy subjects (Shibata et al., 1999; Ainswoth et al., 2000; Kovacic et al., 1996). The purpose of this study was to determine the frequency of recovery of Mycoplasma sp. in throat swabs from healthy subjects.

\section{MATERIALS AND METHODS}

Subjects and specimens: This study was conducted at the Laboratorio de Micoplasmas del, Centro de Investigaciones Microbiológicas, Instituto de Ciencias de la Benemérita Universidad Autónoma de Puebla, México, from September 2008 to July 2009. A total of 210 subjects (142 females and 68 males, age range of $18-24$ years), throat swabs from persons without respiratory tract infections were taken and considered in the study.

Throat samples were collected on cotton-tipped swabs and were put in Eaton medium (PPLO-broth, yeast extract $10 \%$, unheated horse serum $20 \%$, glucose $0.5 \%$, phenol red $0.002 \%$ and penicillin $1000 \mu \mathrm{mL}^{-1}$ ) and incubated at $37^{\circ} \mathrm{C}$ for 30 days or until the phenol red indicator changes color. As soon as the color changes $5 \mu \mathrm{L}$ broth cultures were seeded on Eaton agar plates and stereomicroscope visualized.

DNA extraction and amplification: DNA was extracted from samples by the method described by Sidhu et al. (1995). Primers $\mathrm{AR}_{1}$ sense and $\mathrm{AR}_{2}$ anti-sense were used for amplification of a $301 \mathrm{bp}$ fragment from mycoplasmas DNA.

The sequence of $\mathrm{AR}_{1}$ is 5 'ATG RGG RTG CGG CGT ATT AG $3^{\prime}$ and $\mathrm{AR}_{2}$ is $5^{\prime} \mathrm{CKG}$ CTG GCA CAT AGT TAG CCRT 3. PCR was carried out in a total volume $20 \mu \mathrm{L}$ which includes: PyroStart ${ }^{\mathrm{TM}}$ Fast PCR Master Mix $10 \mu \mathrm{L}$, primer $\mathrm{AR}_{1} 1.3 \mu \mathrm{L}$ primer $\mathrm{AR}_{2} 1.3 \mu \mathrm{L}$, template $\mathrm{DNA} 5$ and $2.4 \mu \mathrm{L}$ water nuclease-free. Amplification was performed in a TC-412 Thermocycler (Techne-USA) with a programme of $5 \mathrm{~min}$ at $95^{\circ} \mathrm{C}$, followed by 40 cycles of 1 min at $95^{\circ} \mathrm{C}, 1 \mathrm{~min}$ at $50^{\circ} \mathrm{C}, 1 \mathrm{~min}$ at $72^{\circ} \mathrm{C}$ and a final step of $5 \mathrm{~min}$ at $72^{\circ} \mathrm{C}$. PCR products were detected by $2 \%$ agarose gel electrophoresis with ethidium bromide staining.

Statistical analysis: Values of Mycoplasma sp. cfu m L $\mathrm{L}^{-1}$ in throat samples from females and males subjects were compared with the Student's t-test.

\section{RESULTS AND DISCUSSION}

The present study was conducted to determine the frequency of recovery of Mycoplasma sp. in throat swabs from healthy subjects. Two hundred ten subjects provided throat swabs of which $142(68 \%)$ and $68(32 \%)$
Table 1: Comparative in the isolations number between genus and cultures mediums

\begin{tabular}{lccc}
\hline Cultures mediums & Subjects & Isolates & Percentage \\
\hline Broth & $142 \%$ & 51 & 36 \\
& $680^{\star}$ & 24 & 35 \\
Agar & 142 ㅇ & 34 & 24 \\
& $680^{\star}$ & 17 & 25 \\
\hline
\end{tabular}

Table 2: Mycoplasma sp. detection between microbiological method and PCR

\begin{tabular}{lc}
\hline Cultures mediums & PCR \\
\hline Broth & \\
$75 / 210$ & $79 / 210$ \\
Agar & \\
$51 / 210$ & $54 / 210$ \\
\hline
\end{tabular}

were female and male genus, respectively. When comparing the number of isolations with respect the genus, appeared the same tendency, there was not statistical difference $\mathrm{p}>0.05$ (Table 1). Mycoplasma sp. detection by PCR present increased in the positive samples number, culturing mycoplasmas can take 14 weeks and can be difficult because of a requirement for special growth conditions. Table 2 shows the general results obtained for the samples evaluated by culture and PCR.

Mcrobiologic diagnosis also has disadvantages, one of which is that Mycoplasma pneumoniae can be recovered from the respiratory tract several weeks after acute infection making it difficult to differentiate current from recent infection (Gil et al., 1993).

When applied to sample, PCR detected Mycoplasma sp. far more frequently than culture. Limited data comparing PCR and culture methods are available. However, PCR was shown to be more sensitive and reproducible than culture for detecting $M$. pneumoniae in throat swabs from experimentally infected hamsters (Bernet et al., 1989). One can hypothesize that culture positivity may be partly related to the presence of a large number of organisms in the samples with the culture system we used.

As many as $25 \%$ of persons infected with $M$. pneumoniae may experience extrapulmonary complications at variable time periods after onset of or even in the absence of respiratory illness. The presence of $M$. pneumoniae in extrapulmonary sites such as blood, synovial fluid and cerebrospinal fluid, pericardial fluid and skin lesions has been documented by PCR as well as culture, so direct invasion must always be considered (Narita et al., 1996). However, the frequency of direct invasion of these sites is unknown because the organism is rarely sought for clinical purposes. It is also important to realize that extrapulmonary complications can be seen before, during or after pulmonary manifestations or can occur in the complete absence of any respiratory symptoms (Cassell and Cole, 1981). 
The lack of reliable commercially shown media in the past effectively prevented many clinical laboratories from offering Mycoplasma sp. detection by culture, even before alternative techniques such as PCR existed. If culture is attempted, isolation of Mycoplasma sp. from nasopharyngeal or throat swabs or lower respiratory tract specimens should be considered clinically significant in most instances but should be correlated with the presence of clinical respiratory disease due to the possibility of asymptomatic carriage (Waites and Talkington, 2004).

Using sensitive PCR-based detection methods, high incidences of $M$. fermentans positivity have noted in several anatomic sites from apparently normal healthy subjects. Data regarding the presence of $M$. fermentans within the human lung or its ability to establish chronic symptomless pulmonary infection, however are severely limited (Gao et al., 2004; Rivera et al., 2008).

\section{CONCLUSION}

In this study, it is interesting to note that mycoplasmal colonization or infections are not necessarily associated with a strong inflammatory response and some mycoplasmas colonize the respiratory and urogenital tracts with no apparent clinical symptoms. It is therefore, tempting to speculate that in addition to triggering the production of proinflammatory cytokines, certain organisms have the capacity to downregulate $\mathrm{NF}-\mathrm{kB}$ or to induced anti-inflammatory cytokines such as IL-4, IL-10, IL-13 or transforming growth factor- $\beta$, contributing to the complex network of synergistic and antagonistic influences induced by mycoplasmas on cells of the immune system. Moreover, mycoplasmas can grow in close interaction with mammalian cells, often silently for a long period of time. However, prolonged interactions with mycoplasmas with seemingly low virulence could through a gradual and progressive course, induce chromosomal instability as well as malignant transformation, promoting tumorous growth of mammalian cells.

\section{REFERENCES}

Ainswoth, J.G., S. Houshid, A.D. Webster, C.B. Gilroy and D. Taylor-Robinson, 2000. Detection of Mycoplasma fermentans in healthy students and patients with congenital immunodeficiency. J. Infect., 40: 138-140.

Baseman, J.B. and J.G. Tully, 1997. Mycoplasmas: Sophisticated, reemerging and burdened by their notoriety. Emerging Infect. Dis., 3: 21-32.
Bernet, C., M. Garret, B. Barbeyrac, C. Bebear and J. Bonnet, 1989. Detection of Mycoplasma pneumoniae by using the polymerase chain reaction. J. Clin. Microbiol., 27: 2492-2496.

Cassell, G.H. and B.C. Cole, 1981. Mycoplasmas as agents of human disease. N. Eng1. J. Med., 304: 80-89.

Gao, F., A. Barchowsky, A.A. Nemec and J.P. Fabisiak, 2004. Microbial stimulation by Mycoplasma fermentans synergistically amplifies IL-6 release by human lung fibroblast in response to residual oil fly ash (ROFA) and nickel. Toxicol. Sci., 81: 467-479.

Gil, J.C., R.L. Cedillo, B.G. Mayagoitia and M.D. Paz, 1993. Isolation of Mycoplasma pneumoniae from asthmatic patients. Ann. Allergy, 70: 23-25.

Keceli, S.A. and R.J. Miles, 2002. Differential inhibition of mollicute growth: An approach to development of selective media for specific mollicutes. Applied Environ. Microbiol., 68: 5012-5016.

Kovacic, R., V. Launay, P. Tuppin, A. Lafeiullade, V. Feuillie, L. Montagnier and O. Grau, 1996. Search for the presence of six Mycoplasma species in peripheral blood mononuclear cells of subjects seropositive and seronegative for human immunodeficiency virus. J. Clin. Microbiol., 34: 1808-1810.

Narita, M., Y. Matsuzono, O. Itakura, T. Togashi and H. Kikuta, 1996. Survey of mycoplasmal bacteremia detected in children by polymerase chain reaction. Clin. Infect. Dis., 23: 522-525.

Razin, S., 1997. The minimal cellular genome of mycoplasmas. Indian J. Bichem. Biophys., 34: 124-130.

Razin, S.H., D. Yogev and Y. Naot, 1998. Molecular biology and pathogenicity of mycoplasmas. Microbiol. Mol. Biol. Rev., 62: 1094-1156.

Rivera, A., L. Cedillo, A. Yanez and S. Giono, 2008. Synergistic interaction between Mycoplasma fermentans and volcanic ash. Arch. Med., 8: 98-106.

Rottem, S., 2003. Interaction of mycoplasmas with host cells. Physiol. Rev., 83: 417-432.

Shibata, K., M. Kaga, M. Kudo, L. Dong and A. Hasebe et al., 1999. Detection of Mycoplasma fermentans in saliva sampled from infants, preschooll and children, adolescents and adults by a polymerase chain reaction-based assay. Microb. Immunol., 43: $521-525$.

Sidhu, M.K., A. Rashidbaigi, D. Testa and M.J. Lia, 1995. Competitor internal standards for quantitative detection of mycoplasma DNA. FEMS Microbiol. Lett., 128: 207-211.

Waites, K.B. and D.F. Talkington, 2004. Mycoplasma pneumoniae and its role as a human pathogen. Clin. Microbiol. Rev., 17: 697-728. 